\title{
PROFILE: SIMON REYNELL
}

\author{
Simon Reynell
}

Simon Reynell is a sound recordist and music producer who lives in Sheffield. For many years he worked in television but for the last 12 years he has spent most of his time running the record label Another Timbre, which has released over 150 CDs. Early releases focused primarily on improvisation, but the balance of the label's output has shifted, and

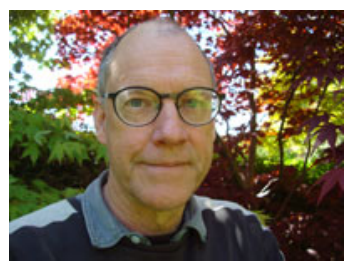

Simon Reynell, photo by Dinah Ward most recent releases have been portrait CDs featuring works by experimental composers. The no-man's land between improvisation and composition remains a strong interest and the work of most of the composers and musicians appearing on the label crosses that space in various ways.

Simon has developed a close working relationship with Apartment House, whose releases on Another Timbre feature music by Laurence Crane, Linda Catlin Smith, Cassandra Miller, Julius Eastman, James Saunders and many others. Other releases of note include the 'Wandelweiser und so weiter' and 'Morton Feldman Piano' box sets and the Canadian Composers Series of $10 \mathrm{CDs}$. He is particularly committed to promoting the music of lesser-known and overlooked musicians and composers, many of whose first CDs have been released on Another Timbre, including Catherine Lamb, Magnus Granberg, Martin Iddon, Luiz Henrique Yudo and Melaine Dalibert.

\section{What first made you decide to start up a record label?}

I've loved both improvised and contemporary classical music since I was about 17, when I discovered Stockhausen and Derek Bailey at about the same time. That is over 45 years ago now. For decades it was just a private passion, as a listener; I never learned to play an instrument to an even half-decent standard. Then about 12 years ago I was getting fed up with my job as a TV documentary sound recordist - what with the advent of reality TV, every programme having to be fronted by a celebrity, etc, etc. My partner told me that I was getting very grumpy and needed to do something else. My kids had grown up and had begun to leave home, so I had more headspace and fewer financial demands. I decided that I'd do less TV work and spend my spare time setting up a CD label. I didn't expect that it would take off in the way it has. It now takes up almost all my time and I hardly do any paid work. So I'm not rich, but life is much more satisfying. 
Your catalogue has a fascinating balance between improvised and composed music. Do you see them as complementary or different sorts of music-making?

I do see them as complementary, and the label's catalogue has a lot of releases that arise from a productive cross-fertilisation of the two. There are countless ways of combining improvisation with composition but it's not easy to do well. Sometimes the results are pretty awful, like the worst sort of crossover music when two things are just jammed together. But when it's done well I find it really compelling. The element of unpredictability can give a freshness and excitement which I feel most fully notated music struggles to achieve (though this can obviously have other strengths).

Cage's number pieces, which I listened to fairly obsessively in the 1990 s before I started the label, opened a door for me personally in this respect. I see a lot of the music I've released as flowing out from that, though some of the composers I've worked with might contest that lineage. But, as I say, there are lots of fruitful ways of combining improvisation and composition and, looking at the label's catalogue, most of the names that keep coming back operate in those spaces where the two overlap: Magnus Granberg, Jürg Frey, John Tilbury, Angharad Davies, Antoine Beuger, Catherine Lamb, Christoph Schiller, Ryoko Akama, John Lely and so on.

\section{There seems to have been a recent tilt in balance towards composed music: is this so and, if so, why?}

Yes, the balance has definitely shifted over the past six years or so, which is something that I neither planned nor would have predicted. Why? The simple answer is that the label's output has followed changes in my personal taste. But behind that lies a shift whereby I have become much more interested in music that works with pitch than I used to be, and less excited by music that is working primarily with timbre or texture.

A turning-point was working with Laurence Crane for about two years, preparing his double CD 'Chamber Works 1992-2009'. I'd always been aware of Laurence's music, and knew that I liked it whenever I heard it, but I kind of held it at arm's length because it was so different from most of what I was listening to. His music uses harmony and simple melodic patterns while somehow maintaining an aura of strangeness. Recording and editing Laurence's pieces I got more and more drawn in to those aspects of music, which up to that point I'd tended to regard as secondary or somehow conservative. So, over a couple of years, my whole way of listening to music was turned on its head. Previously, when I heard a violinist playing a solo piece, after a few minutes I'd start getting frustrated if she or he hadn't started using extended techniques or exploring unusual textures, and I'd say to myself 'come on, get on to the real stuff!' Whereas now, if I hear, say, a violin and electronics piece that is all about exploring different timbres, I find myself getting itchy after a few minutes and thinking 'when is the pitched material going to start?'

At the time it felt like this was a purely personal thing, but actually there were quite a few people in experimental music who were going on a similar trajectory at around the same time. One of those intangible cultural shifts that occurs, like a change of climate. Inevitably, with the shift in my taste towards pitch-based material, composition now figures more prominently in the label's output, as freely 
improvised music doesn't usually do much with pitch that is very interesting. But as I say, I still love it when composed pitched elements are combined with the unpredictability and openness of improvisation.

\section{Why does Another Timbre have that name?}

As I said, when I started the label, I was primarily interested in music that explored unusual textures and timbres, so the label's name was like a description of the music I wanted to release, or perhaps a minimanifesto. Now that my tastes have shifted it doesn't feel so appropriate, but it wouldn't work to change the label name to 'Other Pitches' or whatever. And anyway, it's not like I disavow the early releases it's just that things have moved on over a 12 year period, as they should.

\section{Are there types of music that you would never record?}

I only release music that I really like but, as my tastes continue to shift, it's difficult to categorically say 'never'. A couple of years ago I worked with Apartment House to produce a non-romantic, vibratofree recording of Messiaen's Quatuor pour la fin du temps. Though I've always liked the piece, even five years ago I'd never have predicted actually releasing it on Another Timbre. But it does kind of fit within the label's new direction, and I think it's a beautiful realisation.

I do have some pet-hates or prejudices that rule out a lot of things that I might otherwise be interested in. So, for instance, I don't release much music that involves a singer, and it's not just for financial reasons that I tend to avoid orchestral music. Also, I'm afraid I'm terribly ignorant of (and probably snobbish about) any form of popular music or jazz, etc, so I tend to avoid anything that seems to borrow from or connect with those musics. But I try not to be too dogmatic, and fortunately there are exceptions in all these cases.

Your series of Canadian CDs has probably done more to promote that country's new music, perhaps especially the music of Linda Catlin Smith and Cassandra Miller, than anything else. Do you think there's a particular flavour to the music?

Musically I don't think that there's a particular Canadian style or school. In a way that was what interested me about the composers I worked with: most of them were pretty unique and didn't belong to any movement or tendency. When I did the composer interviews for the booklet which accompanies the series, I asked each of them whether they felt there was anything specifically 'Canadian' about their work, and there were some really good answers. Linda Catlin Smith, who was born in the States and moved to Canada after university, said that in Canada as a composer she felt that she had 'a particular freedom in terms of style and aesthetics. I've always felt free to explore music in my own voice with no pressure to fit in ... We are largely unexamined by the world, left alone to explore and experiment.' That made sense to me. A sense of being slightly out of things, removed from the big international centres and the orthodoxies that build up around them. That can be an advantage in some ways for a composer looking for their own voice.

And I suppose that sense of being somewhat apart has a resonance for me personally. My involvement with contemporary music from 
the age of 17 till $50+$ was as someone listening to recordings alone in my bedroom in Sheffield, hundreds of miles from London, let alone Paris, Darmstadt or New York. Someone without musical training, who can hardly even play a nursery rhyme, but who listens hard and has developed their own tastes without too much regard for what other people think. 